\title{
Urban planning for emergent technologies, new life-styles and a changing environment
}

\author{
R. G. Boothroyd \\ Retired Chartered Engineer, Queensland, Australia
}

\begin{abstract}
Urban designs often cannot be adapted to changing life-styles. Alternatively, some examples may incur prohibitive costs of retrofitting. In today's fast-moving society the urban designer faces an increasing variety of problems. Some of these are considerations which have merely changed. These include urban and interurban transport; waste disposal and recycling; unemployment and workforce mobility; education and recreational facilities. Other considerations are more novel such as developments in manufacturing technology; likely changes in taxation methods; reducing domestic incomes; promotion of racial and religious harmony; retailing, or hiring of products as an alternative; product reliability; alternative ways of dwelling purchase; adapting planning to accommodating changes in climate particularly in high temperature zones. The paper concludes with an outlined large-scale planning proposal using solar power for large-scale electricity supplies integrating the economic and social interests of Europe and Africa This example requires some of the above and some additional considerations.
\end{abstract}

Keywords: urban transformation, sustainability, climate change, economic development, urban integration.

\section{Introduction}

Today increasing uncertainty about a fast-developing future [1, 2] adds an extra dimension to urban design. Yet we have no option but to accommodate such difficulties. For example, due to financial reasons, major buildings still need a design life approaching 100 years and this is an unavoidable fact of life. This paper is concerned with consideration of this uncertain future and how this may influence the design decisions we have to make. 


\section{Financial security, problem management and employment}

Ultimately every area of human habitation has to balance its financial affairs. This happens automatically, whether we try to design it or not. Imbalance can be tolerated only for a limited time. For a small area, such as a single dwelling, this time interval can be quite short before the mortgagor moves in. At the other extreme, large nations, such as the United States, can run up huge debts for decades. The recent problems in Europe illustrate this. Cyprus, a small nation, suddenly faced a crisis, whereas earlier and much bigger problems in Greece, Portugal, Spain and Italy were put on hold until these much more extensive difficulties can be resolved.

Trying to avoid future financial problems in urban design can be very complicated. Designing for internal self-sufficiency and a reduction in external dependency may be useful. Yet trading with other areas will increase the wealth of any society. Where is the correct balance in an era when transport costs are on the rise? Nevertheless solutions to some particular problems may be less perplexing.

\subsection{Coping with unexpected events}

For example it is reasonable to at least suspect that climate change [3] may be a major factor in the recent spate of severe flooding in Australia. Bundaberg, for example, lost much housing on flat land. Should this affected area be rebuilt or should it be rezoned for market gardening and allotments for residents? Flat land in Australia usually commands a premium price because it is cheaper for house construction and it is also more attractive for industrial development. Should local authorities restrict its use for these purposes? Although flooding may destroy an individual crop, it is the natural and inexpensive way to rejuvenate agricultural land. Ancient Egypt relied on natural flooding to preserve soil fertility. Can we work with nature or should we try to control it?

\subsection{Planned industrial development}

Urban designers usually try to attract investment in industrial development. This is partly to offset local unemployment problems. This leads us to another future problem likely to face the urban designer, namely possible major changes in central government legislation. Unemployment in the developed world is becoming such a severe problem that democratic governments will be forced to take some remedial action. In examining unemployment problems one needs to be wary of partisan-inspired shibboleths [4] such as the suggestion that we need to replace our aging workforce. The complexity of modern work often gives an edge to the more experienced worker. The evidence for this is the massive youth unemployment in Spain and other countries, despite the fact that this younger generation is usually better-educated than their seniors.

A major factor causing unemployment today is improvement in sophisticated manufacturing engineering. Machines are now so vastly superior to human factory labour in most cases. Coupled with world-wide marketing of mass- 
produced products and the ability of expensive machinery to work reliably round the clock, we have a situation where human labour is usually uncompetitive. However it makes no sense to reverse this situation because repetitive factory work is usually a trial of human endurance and a reversal of modern techniques would make us pay more for our purchases.

\subsection{Managing unemployment}

Machines are our slaves but perhaps we should ask ourselves if we are also becoming slaves to our machines when we buy another unit to replace a cheaply made one which has been designed deliberately to wear out prematurely. This is another important factor, outside the scope of this paper, namely should it become compulsory for all everyday purchases to meet ISO (International Standards Organisation) requirements. A world with declining resources will eventually make this reform inevitable.

In times of crisis, such as war, governments impose rationing. Using this approach, unemployment seems relatively easy to solve by compulsory jobsharing. In practice this is a very complicated solution because there are so many forms of employment. However in an ordinary employed situation this might take the form of allowing only two days of work per week to be tax-free and taxing people on the number of extra hours they work. Such a radically changed taxation system would apply an incentive for the individual to maximise personal skills to gain a higher wage-rate. Chronic unemployment tends to be associated with lack of skill.

The present 5-day working week might well be considered an intrusion into our private lives if we enjoy our leisure and family time. For such people a 2-3 day working week can become a pleasurable distraction from domestic routine rather than a burdensome 'Monday morning' feeling. Sharing income derivation and domestic chores is becoming more fashionable in modern families. Job sharing seems to fit in with the psychological needs of many of us but not everybody. The problem is that a shorter working week implies a proportionately smaller income so we need to also address methods by which we can trim the household budget.

Declining wage-rates in real terms are already becoming more commonplace in the USA as it strives to become more competitive internationally. This is causing public discontent. Resource depletion, overpopulation and job-sharing will all act to reduce family disposable income in the future. This requires firm steps to curb less important parts of household expenditure whenever we can. In the interests of fairness (see also the following section 3) perhaps we should demand that the machines which replace labour should also be taxed? If such reforms eventuate, and much would depend on international cooperation through the United Nations (UN), this influence on urban design, though subtle, would be extensive.

Again we might try to learn from studying the complexity of "Nature". Modern Darwinian evolutionary theory [5] recognises that life in Nature is both competitive and cooperative and Nature tries to find the optimum balance automatically. It seems that we humans, who seek to control Nature, have to find 
the optimum balance for ourselves. This is not an easy task. It seems reasonable to conclude that it is simplistic to believe either in free enterprise or in a centrally controlled economic system. The art of good political management lies in fusing the two systems together.

There is useful earlier literature in this general area [6, 7] and there are organisations [CASSE, 8] dedicated to making a non-growth economy function adequately. In some well-developed countries a non-growth economy is already being forced upon us.

\subsection{Recycling or refurbishing?}

With the trend towards increasing fuel costs, even small urban communities will be expected to become more self-sufficient. Recycling is normally understood to mean breaking up a discarded product to salvage the materials from which it is made. Refurbishing is repairing a defective item to extend its useful life.

Recycling has the support of manufacturing industry because commercial enterprises wish to sell as many of their products as possible but this produces unnecessary waste in a world of diminishing resources. Due to environmental and social concerns, refurbishing can be expected to become more commonplace and it has the advantage of presenting opportunity for more local employment.

For example, on a small-scale, ten dollar wrist-watches are normally thrown away when the battery is discharged. It is easy for a small street-trader to replace the battery and wristband to produce an acceptable recycled watch. The increasing popularity of street markets in large cities is an interesting social phenomenon and this is where many forms of additional employment opportunity may exist.

On a larger scale, a trader in white goods might be expected, in the future, to rent more items than are sold. The trader's experience qualifies him, as a wholesale purchaser, to select goods with the best durability performance. The general public lacks this skill and relies on specialist magazines for help. Offering a competitive rental service, with in-store servicing, may be more attractive to customers who usually have neither the interest nor the ability in maintaining today's complicated home appliances. Such likely developments are consistent with conservation and are relevant in urban design considerations, particularly regarding their effects on waste disposal of large objects.

\section{Basic facilities for the individual}

\subsection{Housing}

This subject is well covered in the general literature but again this is an area with modern problems which are likely to be remedied by changes in legislation and revised social/commercial tenets.

One such area, which is particularly relevant in highly-competitive western economies, stems from the lack of security in employment. A mere 50 years ago wages were lower but it was possible to secure employment which was 
permanent enough to plan repayment of a 30 year mortgage. Today entire industries can be rendered obsolete in a few months. One such example was the advent of digital cameras which made strip-film processing a part of history. Another advance in technology which has made employment skills outdated is the computerisation of the printing industry. The price of progress can be high for some unlucky individuals. A family man with small children cannot be expected to undergo retraining and pay the mortgage and argue with an insurance company which disputes his claim for unemployment compensation. Why should this family suffer the injustice of losing their home to the mortgage holder, all in the interests of technical progress?

Perhaps a more attractive form of house purchase would be to use the old system of joining a housing cooperative. A whole range of such schemes have been used in the past but usually they were on a small scale. A really large scale scheme would allow an investing member to rent a home anywhere where employment opportunity was available. Changing family circumstances would allow an easy upgrade or downgrade of housing. Investment in the scheme could be combined wholly or partly with superannuation with the option of cash withdrawal by an investing member on retirement. Private and public schemes could run side by side, the latter providing a solution for homeless people with appropriate safeguards relating to tenant responsibility. Mobility of labour would be much improved if the hassle of buying and selling a home can be eliminated.

This is just one of many reforms which are desirable when domestic income declines in real terms. Future social harmony depends on finding various other ways to reduce family expenditure obligations.

\subsection{Public transport}

Traffic congestion in cities has often reached such proportions that many people prefer the discomfort of public transport. Joss et al. [9] have identified the basic problem which causes insufficient patronising of public transport. They [9] suggested a maximum 300m distance of pedestrian travel to access public transport. A recent internationally-applicable suggestion [10] to apply this type of new technology to Brisbane's public transport system was rejected because of high retrofitting costs $[11,12]$.

It seems indisputable [13] that mass car ownership by the World's general public will become impossible as our fossil fuels diminish. This conclusion is independent of any environmental pressures.

It follows that priority for public transport needs serious consideration in the initial design of new urban areas. Car ownership is now much less of a personal status symbol in many affluent societies and its replacement with an alternative personal transport system in cities is now feasible and more socially acceptable. Much the same conclusion concerning personal priorities can be said of the ten dollar wrist-watch, mentioned above, and now worn by so many wealthy people.

We can only conclude that private car ownership in well-developed urban areas now seems to be an outdated and extravagant technology which is unsustainable. A private car is often found to be too large or too small. Household garage space is often wasted space. Personal transport needs to be 
small enough to be kept in a suitcase or stored in a cupboard and this is now feasible technically [10]. On the rare occasions when we need a larger vehicle, we should be able to hire it. This type of vehicle use is only an extension of our present day long-distance travel habits when we hire a vehicle, be it a truck, a taxi, a car or a bicycle, when we reach our destination and then finally leave it where we hired it.

\section{Waste management}

The rising cost of raw materials will be conducive to an expected reduction in the amount of waste requiring disposal by local authorities. Australia is reputed to have the worst waste-producing record by generating $400 \mathrm{~kg}$ of solid waste per person annually despite the nation's active recycling industries. Due to shortage of available space for disposal, our large capital cities cannot sustain this problem indefinitely.

\subsection{Solid waste disposal}

\subsubsection{Disposal of plastic}

Recently the disposal of plastics in landfill has been questioned because of slow leaching of contaminants to groundwater [14]. It seems that the only solution to this problem is the manual segregation of waste at the point of origin, namely the household.

So many of our consumable plastic articles fail prematurely due to lack of stabilisation to the polymer molecule-breaking effects of ultraviolet (UV) light. It is easy to subject plastic articles to accelerated UV protection tests $[15,16]$. The method uses a solar concentrator to simulate 63 years of product exposure in a one year test. This suggests that all marketable articles should have a UV durability certificate to prescribed ISO standards.

\subsubsection{Food distribution, storage and waste disposal}

This is an especially difficult area to develop and yet the need for improvement is obvious because so much of our domestic waste comes from disposable food packaging. Firstly it should be pointed out that food distribution and packaging is probably one of the most fully-developed and reliable technologies we have. Yet the waste it produces is voluminous, attracts vermin, and has a multiplicity of other problems for municipal authorities. Food encapsulation, preservation and shelf-life adequacy are vital in any sustainable society [17-22]. How do we reduce the quantity of disposable canisters and wrappings and yet preserve reliable health standards? The importance of this technology in the sustainability context is illustrated by the fact that food loss in well-developed societies is only $2-3 \%$, whereas losses in societies without good packaging technology often approach 50\% [19].

The task of updating this branch of technology is truly daunting and seems likely to keep relevant technical conferences active for decades. In going back to fundamentals, which seems to be inevitable, we have to even consider the 
functioning and design of the supermarket itself. We have to consider so many points of detail. Even the folding of disposable cardboard boxes is the subject of lengthy specialised technical books [23].

\subsubsection{Medical waste}

Considerable criticism has been directed at the disposal of excessive amounts of medical waste in Australia. It has been argued that much waste can be eliminated and costs reduced by autoclaving, using old-fashioned glass equipment instead of disposable plastic items. The wisdom of this is debatable. Medical practice is mostly a human activity with limited opportunity for automation. People are more prone to error than machines and tragic errors relating to manual autoclaving have taken place overseas.

\subsection{Effluent disposal}

For many years we have coped with the fact that one municipality's effluent is often the drinking water for the next conurbation downstream. One likely area where we may expect to see useful developments lies in the more extensive use of algae in water purification. There are two main basic approaches in exploiting algae:-

\subsubsection{Race-course ponds}

In these systems [24] water - which can be fresh or salty - is circulated slowly in large shallow elliptical ponds and unwanted liquid effluent and waste $\mathrm{CO}_{2}$ are added as nutrients. The fast-growing natural algae are skimmed off, dried by solar energy and can then be subjected to flash-pyrolysis to extract useful chemicals and combustible gases and oil. Apart from application in general municipal waste management, these systems can be used in stand-alone industries such as coal-burning power stations and cement manufacture.

These systems need plenty of space but, with good design, race-course ponds have other possible extra uses in market gardening and public recreation. Algae growth takes place at the pond's surface, not lower in the water, and sailing boats, or fish will cause mixing and this improves algae growth.

\subsubsection{Photobiological reactors}

Significant research [25] is currently underway in these 'closed' algae systems which are more compact but incur greater capital outlays than race-course ponds. The algae are usually genetically-engineered and some species can even be adapted to produce diesel fuel directly [25]. Apart from present problems in making these systems viable economically, genetically engineered algae tend to be sensitive and contamination by more aggressive natural algae is a significant problem.

\section{Recreation facilities}

The trend towards ever-increasing automation in manufacturing industry is so advantageous financially that we need to accept and adapt ourselves to it. There 
seems to be no incentive to try to return to a more labour-intensive society. Consequently, physical exercise resulting from hobbies like home growing of food is likely to become more commonplace and has its place in designed sustainability [26].

This brings us to the social problem of increased leisure time and coping with our surplus human energy. This suggests the need for universal access to further education which will help everyone to make the most of increased leisure in their lives. This includes continuing access to tertiary education, especially at more practical, rather than intellectual level. Community sport will need increased facilities but the development and welfare of the whole person also needs some intellectual stimulation for a meaningful life when employment time is reduced.

\section{Threats to regeneration and sustainability in modern urban society}

So many problems in today's world are of our own making. Yet we usually have the power to rectify these problems if we choose to have the will to do so. The following factors, although outside the control of urban designers, can become relevant is reaching strategic executive decisions.

\subsection{The population explosion}

Uncontrolled population expansion presents widespread economic problems and can become a threat to world sustainability. China's much maligned 'one child policy' can be claimed as useful in developing a more wealthy free-enterprise society.

Some parts of Africa, with reproduction rates nearly four times larger than the rest of the world [27] would make the proposal described in section 7 difficult to achieve unless the extra burden of these high birth rates can be controlled. At least the proposals in section 7 would help to alleviate excessive population pressures.

\subsection{Finding 'correctly-balanced' tolerance in society}

Urban designers can contribute to racial and religious tolerance in society by the provision of appropriate facilities. The United Nations can also contribute by incorporating humanistic tenets in their charter which include the basic social teachings of the major organised religions.

\subsection{Faltering democracy and urban sustainability}

Peace and cooperation are necessary for urban sustainability. However we now live in an era when democracy itself is under challenge.

Even in a new and multicultural nation like Australia we have not escaped this same malaise. Public protest groups such as the 'GetUp' Organisation [28] are commonplace. 
Our conclusion must surely be that democracy is still very much alive but we need to ask ourselves if democracy is working well enough for urban sustainability.

\subsection{Revised taxation methods to improve future sustainability}

Trying to predict changes in taxation methods is the bane of many chief executives and the senior urban designer is unlikely to be excluded from this group.

The burden of reducing domestic income will also bring pressure to transfer taxation away from lower income groups, probably towards the original source of wealth generation.

Recently 11 nations in the EU, including the four largest, have decided to introduce the Tobin tax at $0.1 \%$ from January 2014. Boyle [29] has reviewed the broader implications of introducing the Tobin tax including its advantages as a source of revenue for the UN.

The Tobin tax is considered compatible with the need, suggested in the present paper, to shift taxation away from individuals to the point of initial wealth production

\section{Example of a project contributing to good urban design: Reducing $\mathrm{CO}_{2}$ emission in Europe and developing a new clean manufacturing economy in Africa}

Contraction of the world economy to achieve sustainability does not necessarily imply grossly reduced living standards or more limited opportunity for commercial enterprise. Extra potential for advantageous investment tends to present itself whenever we face a serious world-scale problem such as climate change. Moreover good design in urban sustainability should always incline towards maximising a varied number of benefits towards wider society in general. The following example illustrates these points.

This large and important project [30] originated many years ago in the early days of the Club of Rome but it appears to have stagnated. However we now have much improved technology to make the project viable. Also, for illustrative purposes at the present conference, reviewing this project is "dialectic", uses "mutually beneficial forms" and is "integrative" [31].

Fig. 1 shows a relatively small 20 MWE concentrating solar tower (CST) power station. Rows of sun-tracking mirrors (heliostats) concentrate the sun's rays on the top of the central tower where there is a heat exchanger. These power stations are already operating and becoming more competitive with coal-burning plant. They operate continuously as ' $24 / 7$ ' base-load generators by storing heat energy in molten potassium/sodium nitrate at $550-650^{\circ} \mathrm{C}$ for night time use. This heat operates the normal steam cycle used in coal-fired generators. These solar power stations use air cooling for the condensers so that these plant are almost independent of water supply. In the Sahara desert there is no serious problem with installing large numbers of such units, each one generating up to 250 MWTh. 


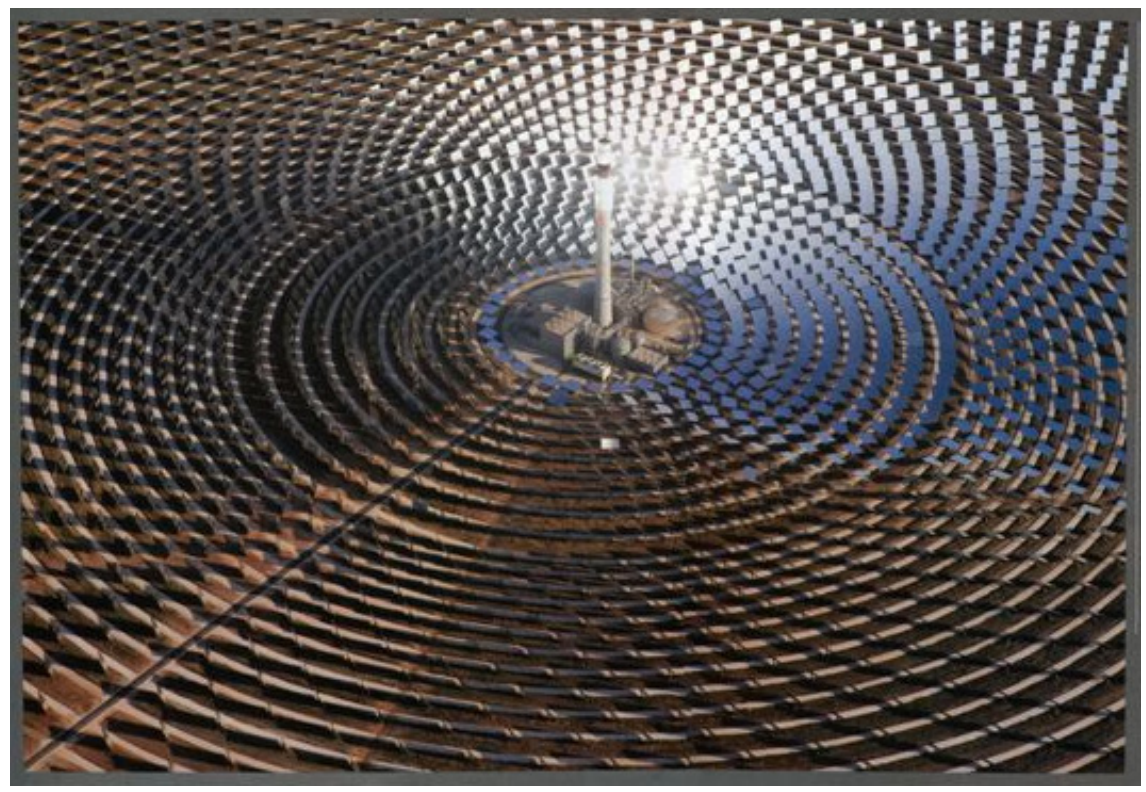

Figure 1: $\quad$ CST Power Station (Gemasolar near Seville in Spain). Note that the photograph has been adapted for the New Scientist by Markel Redondo in order to emphasise that these plant also generate electricity at night.

The Desertec project has been evaluated financially. A similar independent fully-costed proposal [32] to use this system to replace all of Australia's coalburning power stations within 10 years has fallen on deaf ears in a national economy dominated by global coal-mining corporations. Problems arising between large global corporations and less powerful responsible regulatory state governments have been addressed elsewhere [33].

Europe already uses solar energy on a limited scale and those nations bordering on the sea make use of large offshore wind-farms in windy estuaries. However wind power needs CST solar power to provide a stable large scale system [32].

After the Fukushima disaster, Germany decided to discard nuclear power and is now faced with the retrograde step of moving back to coal-fired power generation. As an alternative it is suggested that Desertec's proposal should be advanced to fruition by seeking an alternative form of treaty with North African countries. Only about $25 \%$ of the Sahara desert is unsuitable for CST power stations.

High voltage Direct Current (HVDC) power transmission is also welldeveloped. Fig. 2 shows the existing/planned network for Europe. Undersea HVDC cables have operated reliably for several years. Conversion to AC (alternating current) for power distribution is an additional expense involving 


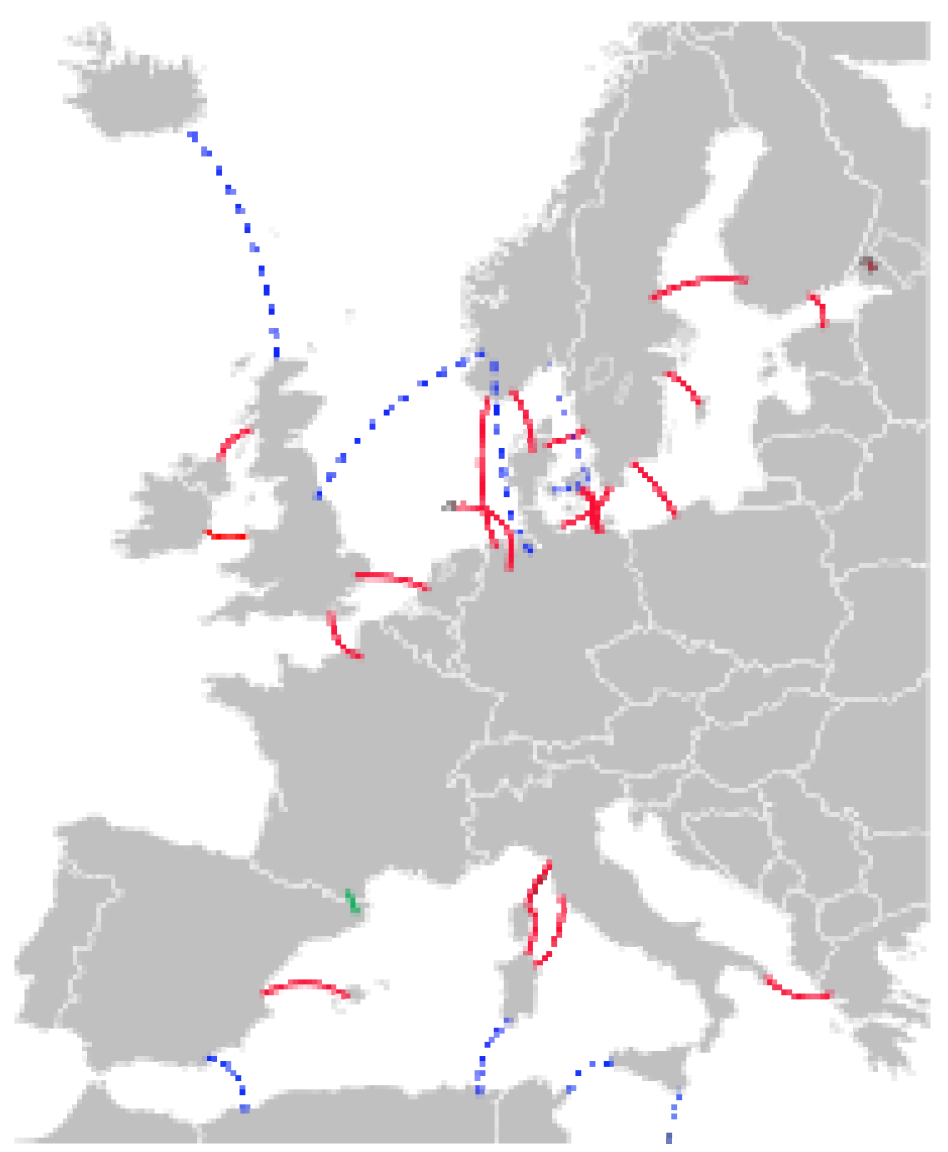

Figure 2: $\quad$ HVDC links. Existing links are shown as solid/red. Planned links shown as dotted/blue. The two left hand dotted links across the Mediterranean sea would also be the approximate positions of the rail ferry links. Two additional links would connect Greece and Southern Italy.

more complex equipment and maintenance but HVDC is found overall to be much superior to AC in long distance transmission of electricity.

The supply of all of Europe's extra power requirements from North Africa would be an attractive proposition if political, social and religious instability problems can be overcome. This seems to be a 'chicken and egg' situation. North Africa's social instability problems seem to arise largely from a low level of international investment which results in unemployment, low incomes, tribal disputes over limited resources, and a widespread feeling of no hope for a better future [34]. It is felt that these problems can be eliminated largely by stimulating investment for which safeguards and stability are needed. 
Perhaps North African countries can lease the land needed for power stations and their HVDC corridors in perpetuity? Perhaps these leases could be granted to a neutral body such as the United Nations so that these resources of common interest to both continents have a status similar to those enjoyed by UNESCO World Heritage sites? Such a system would preserve sovereign integrity. Is this a better recipe for large-scale investment in developing countries than the approaches we use today which are, with some justification [34], usually treated with suspicion?

In an earlier more futuristic study [35] the need for two new intercontinental mainline rail networks was mooted. One of these would connect North Africa with Europe. Possible implementation of this earlier study [35] is still many years into the future and this particular proposal has the disadvantage of requiring a substantial initial investment in research/development. By contrast Saharan solar power generation for Europe does not have this disadvantage because it can be constructed at short notice with existing technology and in much smaller increments so that income can be derived before total completion of the project.

Much attention has already been directed at either building a bridge or a tunnel across the straits of Gibraltar. This would be an expensive and difficult undertaking. There are good reasons for rejecting the tunnel/ bridge concept completely in favour of the much cheaper and more flexible old-fashioned railway ferry system. The reasons for this are twofold.

Firstly each North African country needs to have independent access to such a scheme and this requires at least 5 crossing points. Secondly shorter rail distances improve efficiency. Only one completely land-based rail line is possible, namely one which passes Israel and the other neighbouring countries. Would such a rail link promote peace in this area if the corridor was leased to the United Nations? Certainly such a link would open up all Middle East manufacturing to huge European markets. Improved Middle-East economies are likely to be the best catalyst available to us if we are ever to achieve a lasting peace in this area.

Cheap Saharan solar power can also be exported southwards to further develop manufacturing economies of Equatorial Africa. This area supports the dense populations which are advantageous in a manufacturing economy.

The Desertec proposals, when combined with the rail links proposed here, are likely to be in Europe's best future economic interests. The powerhouse of the world economy is shifting from the West to the East. As living standards improve in nations like China and India, wages will rise so that a younger African manufacturing economy can be expected to have the economic edge. It's not just a matter of lower wages in developing countries but investment in more up-to date machinery. After the destruction of their infrastructure in the Second World War, Germany and Japan enjoyed much post war prosperity largely for this reason.

Also it seems likely that an Africa/European economic union may be replicated in the Far East. If old enmities can be forgotten, Japan, as a technologically innovative nation, could aspire to buying much of its electricity 
from the deserts of North West China. It is suggested that time will probably show us that nations are inherently dependent on each other and cooperation, with controlled and limited competition only, is the best path to take.

\section{General conclusions}

Earlier studies [9, 31] have also demonstrated that urban sustainability is a most complicated and multi-faceted subject and this paper has only considered a tiny part of the subject's details. Also in the space of this paper it has been impossible to attend to some of the fine detail which can be extremely important. For example the concept of worldwide compulsory ISO standards cannot be applied to those technologies in a fast rate of development. Industries vary enormously and cannot be treated equally. Electronic device design technologies are moving so fast that it is even near impossible to agree to industry-based standards.

The technical aspects in this subject, such as opting for one of the many solar options for air conditioning instead of outdated traditional high energy consuming systems, are often self-evident. Also these technical considerations can be less important than some of the social engineering aspects also covered in this paper.

Nevertheless the urban designer can now access huge resources of relevant information [36-41] to tackle a particular problem. We have the LEEDNeighbourhood Certification scheme [38]. We have the accumulated past wisdom of countless thousands of people to guide us in maintaining urban sustainability. If we can manage to harness this huge resource there is little excuse for failure.

International cooperation is essential in tackling climate change which is a necessary precursor to achieving sustainability. The likely increasing role of the United Nations has been mentioned several times in this paper. Combining such suggestions with a possible contribution by ISO Standards (also conveniently located in Geneva) for sustainability, we have a potential situation of direct involvement of the UN in general taxation and trading practice for all member countries. This could give the UN the financial independence it needs to be more effective in international affairs. This alone would be a major contribution in maintaining a sustainable world.

\section{References}

[1] Taylor, G., Evolutions Edge: the coming collapse and transformation of our world, New Society Publishers: BC Canada, 2008.

[2] Gilding, P., The Great Disruption, Bloomsbury: New York, 2011.

[3] Hansen, J., Storms Of My Grandchildren, Bloomsbury: New York, 2009.

[4] Oreskes, N. \& Conway, E., Merchants of Doubt, Bloomsbury: New York, 2011.

[5] Nowak, M.A., Sasaki, A., Taylor, C. \& Fundenberg, D., Emergence of cooperation and evolutionary stability in finite populations. Nature $\mathbf{4 2 8}$ (\#6983), pp. 646-650, 2004. 
[6] Rifkin, J., The End of Work: the decline of the global labour force and the dawn of the post-market era, Putnam: New York, 1995.

[7] Ayres, R. U., Turning Point: an end of the growth paradigm, Earthscan: London, 1998.

[8] CASSE (Centre for the advancement of the steady state economy) http:// steadystate.org

[9] Joss, S., Tomozeiu, D. \& Cowley, R., Eco-city indicators: governance challenges. WIT Transactions on Ecology and the Environment, 155, pp. 109-120, 2010.

[10] Boothroyd, R. G., Replacing the private motor car with a more attractive public transport system. Paper 1061, General Proceedings, $12^{\text {th }}$ World Conf. on Transport Research, Lisbon, 2010.

[11] Fyfe, S. Personal communication, 21 September 2009, Principal Adviser, Dept of Infrastructure and Planning, Queensland Government, Australia.

[12] Baskerville, T. Personal communication, 10 September 2009, Executive Director, Road Business Strategy, Queensland Government, Australia.

[13] Hook, M. \& Aleklett, K., A review on coal-to-liquid fuels and its coal consumption. Int. J. Energy Res., 34, pp. 848-864, 2010.

[14] Rochman, C.M., Browne, M.A., et al., Classify plastic waste as hazardous. Nature 494, (no 7436), pp. 169-171, February 14, 2013.

[15] Lewis, P. R., Forensic Polymer Engineering, CRC Press: London, 2010.

[16] Lewis, P. R., Reynolds, K. \& Gagg, C., Forensic Materials Engineering: Case studies, CRC Press: London, 2004.

[17] Denison, E., \& Cawthray, R., Design Fundamentals: Packaging Prototypes, Rotovision S.A: Crans pres Celigny, Switzerland, 1999.

[18] Emblem, A. \& Emblem, E., Packaging -Prototype Design FundamentalsClosures Rotovision S.A.: Crans pres Celigny, Switzerland, 2000.

[19] Denison, E. \& Ren, G.Y., Design Fundamentals-Packaging PrototypesThinking Green, Rotovision S.A.: Hove (UK), pp. 12-44, 2001.

[20] Re, M. S., Santana. A. \& D’Avilo, M.A., Encapsulation technologies for modifying food performance. (Chapter 7) Innovation in food engineering: new techniques and products, eds Passos, M.L. \& Ribeiro, C. P., CRC (Taylor and Francis): London, pp. 223-275, 2010.

[21] Lagaron, J. M. \& Rubio, A. L., Latest developments and future trends in food packaging and biopackaging (chapter 16) Innovation in food engineering: new techniques and products, eds Passos, M. L. \& Ribeiro, C. P., CRC (Taylor and Francis): London, pp. 485-508, 2010.

[22] De Souza, A. C., Ditchfield, C. \& Tadini, C.C., Biodegradable films and biopolymers for food industries (Chapter 17) Innovation in food engineering: new techniques and products, eds Passos, M.L. \& Ribeiro, C. P., CRC (Taylor and Francis): London, pp. 511-537, 2010.

[23] Wybenga, G. L. \& Roth, L., The Packaging Designer's Book of Patterns (4 $4^{\text {th }}$ edn), Wiley: Hoboken, NJ, pp. 1-705, 2012.

[24] Boothroyd, R. G., Exploiting algae as a biofuel feedstock and for reduction in $\mathrm{CO}_{2}$ emission, January $5^{\text {th }} 2007$, http://oilgae.com/ref/sub/sub1.html 
[25] Anon., The rush towards renewable oil, New Scientist, 203, pp. 61-62, 21 May 2011.

[26] Modaleno, I. M., Cultivating our cities, WIT transactions on Ecology and the Environment, 162, pp. 183-192, 2012.

[27] Knudsen, L., Reproductive Rights in a Social Context, Vanderbilt University Press (Angus and Robertson): Nashville, Tennessee, USA. 2006.

[28] GetUp, www.getup.org.au

[29] Boyle, N., 2014: how to stop the next world crisis, pp. 93-96, Continuum International: London, 2010.

[30] Desertec Foundation. www.desertec.org/concept/questions-answers.

[31] Imam, A., From dichotomy to dialectic: practising theory in urban design. Journal of Urban Design, 16(2), pp. 257-277, 2011.

[32] Wright, W. \& Hearps, P. (lead authors) et al. Zero Carbon Australia Stationary Energy Plan ( $2^{\text {nd }}$ Edn), University of Melbourne Energy Research Institute, June 2011.

[33] Boothroyd, R. G., Let's have a new Wiki for a free flow of information, Australian Rationalist, 81(4), pp. 41-45, 2008.

[34] El Mostafa, J., Local alternatives to Desertec initiatives in North Africa. (5 ${ }^{\text {th }}$ February, 2013) www.africavenir.org/.../local-alternatives-to-desertecinitiative-in-north-africa.html...

[35] Boothroyd, R. G., A proposed extra international air corridor along the world's equatorial belt, paper 1067, General Proceedings, $12^{\text {th }}$ World Conf. on Transport Research, Lisbon, 2010.

[36] Various authors (special issue), The folly of growth: how to stop the economy killing the planet, New Scientist, 200(\#2678), pp. 40-54, $18^{\text {th }}$ October, 2008.

[37] Flannery, J. A. \& Smith, K. M., Eco-Urban Design, Springer: Berlin, 2011.

[38] Farr, D., Sustainable Urbanism: urban design with nature, Wiley: New York, pp. 31-104, 2011.

[39] Cuesta, R., Sarris, C., Signoretta, P. \& Moughlin, J.C., Urban Design: methods and techniques, Taylor and Francis: Hoboken, pp. 201-204, 2012.

[40] Saunders, W., S. \& Krieger, A., Urban Design Looking Forward, Univ. of Minnesota: Minneapolis, pp. 285-290, 2009.

[41] Dobbins, M., Urban Design and People, Wiley: Chichester, pp. 28-31, 2011. 